\title{
DILEMAS DA PRODUÇÃO DE QUEIJO COLONIAL ARTESANAL DO SUDOESTE DO PARANÁ
}

\author{
Fabiane Picinin de Castro Cislaghi ${ }^{1}$, \\ Andréa Cátia Leal Badaró ${ }^{2}$
}

\begin{abstract}
Resumo: Reconhece-se como queijo Colonial um produto elaborado por pequenos agricultores familiares da região Sul do Brasil, sendo um dos mais consumidos pela população na região Sudoeste do Paraná e considerado parte da cultura dos indivíduos nesta região. É uma alternativa para agregar valor à produção de leite e aumentar a renda dos pequenos produtores, com importante papel na economia da região. Este artigo relata as principais ações já realizadas por alguns projetos desenvolvidos sobre o queijo Colonial artesanal do Sudoeste do PR, como o mapeamento dos produtores, elaboração e publicação de materiais didáticos, ações de qualificação realizadas com os produtores, descrição do processo produtivo, análises da água e leite, além da caracterização físico-química, microbiológica e sensorial dos queijos. Apresenta um breve histórico da criação da APROSUD e descreve também as questões legais que envolvem a produção de queijos artesanais, assim como os desafios que ainda precisam ser enfrentados para legitimar o queijo Colonial artesanal do Sudoeste do Paraná.
\end{abstract}

Palavras-chave: Leite cru. Queijo artesanal. Queijo Colonial.

\section{DILEMMAS OF COLONIAL ARTISANAL CHEESE PRODUCTION IN THE SOUTHWEST OF PARANÁ}

\begin{abstract}
Colonial cheese is recognized as a product made by small family farmers in the Southern Region of Brazil, being one of the most consumed by the population in the Southwest Region of Parana and considered part of the culture of individuals in this region. It is an alternative to add value to milk production and increase the income of small producers, with an important role in the region's economy. This article reports the main actions already carried out by some projects developed on artisanal Colonial cheese from Southwestern PR, such as mapping producers, preparing and publishing teaching materials, qualification actions carried out with producers, description of the production process, analysis of water and milk, in addition to the physical-chemical, microbiological and sensory characterization of cheeses. There is a brief history of the creation of APROSUD and the legal issues surrounding the production of artisanal cheeses are also described, as well as the challenges that still need to be faced to legitimize artisanal Colonial cheese from Southwest Paraná.
\end{abstract}

Keywords: Raw milk. Artisanal cheese. Colonial cheese.

\section{Introdução}

A denominação "Colonial" refere-se aos produtos tradicionalmente processados nos estabelecimentos rurais pelos pequenos agricultores familiares da região Sul, em sua maioria descendentes de imigrantes italianos, alemães e poloneses - os 'colonos'. Assim, "colonial” faz referência a certa cultura e tradição, ligada ao saber-fazer dos agricultores, ao seu modo de vida, a suas formas específicas de ocupar o território e fazer agricultura, atributos que são valorizados

\footnotetext{
${ }^{1}$ Docente da Universidade Tecnológica Federal do Paraná (UTFPR), campus Francisco Beltrão, Departamento de Ciências Agrárias. Pesquisadora da Rede de Pesquisas em Queijos Artesanais Brasileiros (REPEQUAB). E-mail: fabianecastro@utfpr.edu.br

${ }^{2}$ Docente da Universidade Tecnológica Federal do Paraná (UTFPR), campus Francisco Beltrão, Departamento de Ciências Agrárias. Pesquisadora da Rede de Pesquisas em Queijos Artesanais Brasileiros (REPEQUAB). E-mail: andreabadaro@utfpr.edu.br
} 
pelos consumidores. O consumo de produtos coloniais pode ser visto como um sinal de valorização da agricultura familiar tão impregnada de valores e de conhecimentos tradicionais, com potencialidade de ir além de simples produtora de matérias-primas e produzir produtos diferenciados. Além disso, os produtos coloniais podem ser vistos como uma alternativa para que o "colono" consiga manter-se de forma digna no meio rural (DORIGON, 2008).

O queijo Colonial é um dos mais procurados e aceitos pela população na região Sudoeste do Paraná, uma vez que tem origens antigas e se tornou parte da cultura dos indivíduos nesta região. É uma variedade que surgiu como uma alternativa para agregar valor à produção de leite e aumentar a renda dos pequenos produtores, tendo importante papel na economia da região (SILVA et al., 2015). Tradicionalmente, o queijo Colonial do Sudoeste do Paraná é fabricado com leite cru, comercializado após poucos dias de maturação e é considerado um produto artesanal. Tem suas características relacionadas ao ambiente onde é produzido e o "modo de fazer" tradicional, expressando a história das famílias que há tempos o elaboram, mantendo uma tradição de várias gerações.

Segundo a regulamentação legal brasileira, define-se alimentos artesanais de origem animal aqueles produtos elaborados com matérias-primas obtidas de produção própria ou de origem determinada, usando-se técnicas predominantemente manuais, adotadas por indivíduos que tenham o domínio integral do processo produtivo, sendo que o produto final é individualizado, genuíno e mantém a singularidade e as características tradicionais, culturais ou regionais (BRASIL, 2019a). A legislação ainda define queijo artesanal aquele elaborado por métodos tradicionais, com vinculação e valorização territorial, regional ou cultural, conforme protocolo de elaboração específico estabelecido para cada tipo e variedade (BRASIL, 2019b).

Não se consideram queijos artesanais aqueles feitos em indústrias de laticínios. Na elaboração de queijos industriais, frequentemente faz-se a pasteurização e padronização do leite, o qual é obtido de diversos produtores. Além disso, é adicionado um fermento comercial, com composição conhecida, o que possibilita a obtenção de um produto padronizado.

Na fabricação de queijos artesanais, não existe padronização de processo e nem de produto, o que é inerente a produtos artesanais e faz com que cada queijo seja único. É preservado o saberfazer, a singularidade e a diversidade. A utilização de leite cru permite a fabricação de queijos típicos da região, com características sensoriais decorrentes da microbiota endógena que se desenvolve no queijo. A identificação de uma região produtora tradicional se revela com a história, com o modo de produção, com as características do solo, do clima, e outros tantos fatores e processos que criam o chamado terroir (MATOS; LA ROVERE, 2020). Terroir é um termo de origem francesa, que tem sido cada vez mais aceito para queijos. Está relacionado ao território e 
ao ambiente particular de uma região, o que irá expressar a qualidade, tipicidade e identidade de um produto (BOTTELLI, 2020).

A região Sudoeste do Paraná é formada por 42 municípios, tendo como principais cidades Dois Vizinhos, Pato Branco e Francisco Beltrão, totalizando 625.735 habitantes, de acordo com estimativa do IBGE (IBGE, 2017), sendo que grande parte da população vive no meio rural (ROCHA; BARCHET, 2015). Destaca-se na região a agricultura familiar, baseada na produção e na transformação artesanal de alimentos no interior da própria propriedade rural. A região é a principal bacia leiteira do estado, com expressiva produção de queijos (FREITAS EDUARDO, 2008; SALDANHA, 2014; SEAB/DERAL, 2020).

Dado este contexto, o objetivo deste artigo é relatar as experiências de projetos de Pesquisa e Extensão com o queijo Colonial artesanal do Sudoeste do Paraná, desenvolvidos na Universidade Tecnológica Federal do Paraná (UTFPR), campus Francisco Beltrão, desde 2016, tendo como parceiros o Ministério da Agricultura, Pecuária e Abastecimento (MAPA), Instituto de Desenvolvimento Rural do Paraná (IDR-PR) e Central Cresol Baser. Dentre as principais ações desenvolvidas pelos projetos aqui relatados, estão o mapeamento dos produtores, elaboração e publicação de material didático (livro), ações de qualificação, apoio na criação da APROSUD, descrição do processo produtivo, análises da água e leite e a caracterização dos queijos.

\section{Mapeamento dos produtores}

Foi realizado um diagnóstico para identificação dos produtores de queijo Colonial artesanal existentes na região Sudoeste do Paraná, definindo municípios e localidades. Através de um questionário e/ou visitas in loco, foram coletados dados sobre o número de animais (vacas) da propriedade, volume de leite e queijo produzidos. Estima-se que o número de produtores da região seja muito maior do que o obtido no mapeamento, pois alguns produtores tiveram receio de informar que produziam queijo, devido à condição de clandestinidade. Além disso, em alguns municípios, não foram informados os dados sobre a produção de queijo Colonial artesanal.

Por meio do mapeamento, foi possível observar que a região Sudoeste do Paraná é caracterizada por pequenos produtores de queijo Colonial artesanal, sendo que a maioria (cerca de $60 \%$ ) das propriedades têm até 5 animais na produção do leite e o volume total de leite produzido diariamente é pequeno, de até 50 litros. Cerca de $70 \%$ das propriedades produzem até $5 \mathrm{~kg}$ de queijo por dia. Nem todo o leite produzido diariamente na propriedade é destinado à fabricação do queijo, pois alguns produtores vendem parte do leite para os laticínios. Esses dados são muito 
importantes para aprofundar o conhecimento acerca das condições de produção deste queijo e para a valorização do produto (CASTRO-CISLAGHI et al., 2019).

\section{Material didático - livro}

Foi elaborado o livro "Segurança alimentar na produção de queijo Colonial artesanal", composto por dois volumes, com linguagem acessível e simples, com o objetivo de orientar os produtores quanto às Boas Práticas de Produção e Processamento do queijo Colonial artesanal. Diferentes profissionais da área, tanto de Universidades, como do MAPA e da Emater - PR (IDRPR) contribuíram na elaboração deste livro.

Este material didático foi utilizado no curso de qualificação, realizado no decorrer do projeto, e também adotado para o trabalho de formação no Sistema Cresol, parceiro do projeto. O livro impresso foi disponibilizado para os produtores, Emater e demais inscritos no curso. Além disso, a versão digital está disponível para download gratuito em: http://leite.fb.utfpr.edu.br/site/index.php/materiais-para-download/ e vem sendo amplamente divulgada para todos os interessados. O material é uma forma de consulta rápida para os produtores e técnicos de extensão rural (BADARÓ; CASTRO CISLAGHI, 2019; CASTRO CISLAGHI; BADARÓ, 2019).

\section{Ações de qualificação}

Com base nas informações coletadas na etapa de mapeamento, foi elaborado e oferecido a todas as queijarias da região um curso sobre as normas básicas de produção segura de queijo, contemplando itens necessários para melhoria da qualidade e da segurança do queijo Colonial artesanal, sem, contudo, modificar a essência do modo tradicional de fabricação já utilizado pelos produtores da região. O curso, composto por 14 módulos, abordou tópicos como: obtenção higiênica do leite, boas práticas de fabricação, sanitização e higiene ambiental para agroindústrias, tecnologia de fabricação, microbiota e maturação de queijos, gestão da qualidade, legislação, rotulagem, entre outros. O público-alvo abrangeu as agroindústrias e produtores que fabricam queijos na região Sudoeste do Paraná, agentes de assistência técnica e extensão rural, agentes de inspeção, profissionais da área e estudantes.

Além do curso, foram realizadas orientações técnicas in loco, palestras e intercâmbio com outras regiões produtoras (APROCAN - Associação dos Produtores de Queijo Canastra). Com a impossibilidade de realizar atividades presenciais em 2020, foi realizada uma live sobre Queijos artesanais e agregação de valor, a qual foi transmitida pelo youtube e facebook. 


\section{Associação dos Produtores de Queijo Artesanal do Sudoeste do Paraná (APROSUD)}

Em outubro de 2019 foi fundada a APROSUD - Associação dos Produtores de Queijo Artesanal do Sudoeste do Paraná. A APROSUD é uma conquista importante para os produtores e agroindústrias de pequeno porte, pois fortalece a valorização dos queijos artesanais na região, dá visibilidade e favorece a articulação política. A APROSUD incentiva a formalização dos produtores e prima pela qualidade dos queijos produzidos, mas ao mesmo tempo preserva o saberfazer e a história por trás de cada queijo.

Atualmente, a APROSUD é composta por 18 produtores associados e conseguiu o apoio financeiro e técnico da Cresol e do Sebrae-PR, além das parcerias já estabelecidas com IDR-PR, MAPA, SEAB, UNIOESTE e UTFPR. No final de 2019 e início de 2020, os produtores participaram de eventos com exposição e degustação dos queijos. Após março de 2020, foram realizadas capacitações à distância e foi elaborado o plano de ação para 2021, junto às instituições parceiras.

Para a maioria dos associados da APROSUD, a venda do queijo representa mais da metade da renda total e para aqueles que estão começando a produzir, o objetivo é aumentar a proporção desta renda. Cerca de metade dos associados gostaria de ampliar a produção, o restante está satisfeito. Em relação à inspeção, 11 produtores possuem registro no Serviço de Inspeção Municipal (SIM) e os demais gostariam de ter, pois a inspeção é um meio de passar para os consumidores que o produto vendido é seguro e de qualidade, além de possibilitar a comercialização. As vendas do queijo Colonial artesanal são realizadas principalmente de forma direta ao consumidor, mas também são vendidos em feiras, em supermercados e para alimentação escolar. O preço do quilograma do queijo varia de $\mathrm{R} \$ 18,00$ a $\mathrm{R} \$ 45,00$ (PASTRO et al., 2020).

\section{Premiações do queijo Colonial artesanal do Sudoeste do Paraná}

Os queijos artesanais da região Sudoeste do Paraná já foram premiados em concursos nacionais e internacionais. Nos anos de 2017 e 2018 foi promovido pela Emater-PR (IDR-PR) o I Concurso de Queijos Artesanais do Paraná, com o objetivo de valorizar a cultura alimentar e o saber-fazer dos queijos artesanais e, assim, contribuir para a agregação de valor por meio do desenvolvimento da agroindústria. O primeiro colocado neste concurso estadual foi um queijo Colonial de Itapejara d'Oeste.

Em 2019, um queijo de Chopinzinho recebeu medalha de prata no Mundial de Queijos do Brasil em Araxá-MG. No mesmo ano, os produtores da região foram premiados com medalhas de ouro, prata e bronze no V Prêmio Queijo Brasil, em Florianópolis-SC. 


\section{Tecnologia de fabricação do queijo Colonial artesanal}

O queijo Colonial artesanal é obtido pela coagulação enzimática do leite cru por meio do coalho. Cada produtor tem o seu modo de fazer, que frequentemente foi passado de geração a geração. Além disso, pode existir uma variabilidade sensorial entre os diferentes lotes do mesmo produtor, o que é característico de queijos artesanais.

Os queijos Coloniais são elaborados com leite de vaca, de diferentes teores de gordura, variável de acordo com a raça dos animais, alimentação, entre outros fatores. O desenvolvimento do sabor e aroma em queijos de leite cru deve-se principalmente à variada microbiota endógena existente e enzimas naturais do leite. Fatores como o clima, a pastagem e outras características regionais também têm influência nas características sensoriais dos queijos (SOBRAL et al., 2017). Em alguns queijos Coloniais ocorre a formação de olhaduras propiônicas devido à presença de bactérias propiônicas selvagens.

A legislação prevê que, por se tratarem de produtos de origem animal, mesmo sendo artesanais, os queijos precisam estar submetidos ao controle do serviço de inspeção oficial e atender algumas exigências. Todo o processo produtivo deve adotar Boas Práticas de Fabricação (BPF) visando garantir a produção de um alimento seguro ao consumidor. Além disso, os locais onde são produzidas as matérias-primas devem adotar Boas Práticas Agropecuárias (BPA) (BRASIL, 2019a). A utilização de leite cru só é permitida para propriedades certificadas como livre de tuberculose e brucelose. Além disso, a propriedade deve participar de programa de controle de mastite, controlar e monitorar a potabilidade da água utilizada na ordenha e na fabricação do queijo e implementar a rastreabilidade de produtos (BRASIL, 2019b).

O leite para fabricação do queijo Colonial deve ser o mais fresco possível, ou seja, obtido e utilizado em um intervalo de tempo pequeno. Alguns produtores também adicionam uma pequena quantidade de iogurte natural ao leite, o que contribui para uma acidificação mais rápida. O queijo Colonial é um queijo de massa semicozida ou cozida, dessorada, moldada, prensada, salgada e maturada. A cocção da massa, quando realizada, frequentemente é feita pelo método indireto, através do aquecimento da parede do tanque. Essa intensidade do tratamento térmico (tempo e temperatura) dado à massa interfere na umidade do queijo. Na maioria das vezes, a salga é feita a seco (na superfície do queijo) ou na massa. A salga no leite ou em salmoura são muito pouco utilizadas pelos produtores.

O queijo Colonial é maturado pelo tempo necessário para o desenvolvimento das características sensoriais típicas. Durante a maturação ocorrem mudanças microbiológicas, físico- 
químicas e bioquímicas que originam compostos diversos, alterando o sabor, aroma, consistência e cor do queijo. Existe grande variabilidade entre os produtores em relação às condições de maturação, o que contribui para a diversidade de queijos Coloniais artesanais na região.

Inicialmente buscou-se determinar um período mínimo de maturação que garantisse a inocuidade dos produtos, a exemplo de outras regiões produtoras, como Minas Gerais. No entanto, esse período é diferente para cada produtor, pois diversos fatores interferem nesse processo, como o tamanho, umidade, teor de sal e pH do queijo, microbiota do leite, tecnologia de fabricação, temperatura e umidade relativa do ambiente de maturação. A maturação não deve ser entendida como etapa para reduzir a contaminação microbiológica, mas sim como etapa tecnológica. Se a matéria-prima for de baixa qualidade e não forem seguidas as BPF, nem os 60 dias serão suficientes para garantir inocuidade. Da mesma forma, não é possível obter um queijo de boa qualidade a partir da pasteurização de um leite com elevada carga microbiológica. Além disso, práticas de higiene deficientes pós pasteurização podem levar à contaminação do queijo. A utilização de leite de boa qualidade, obtido de animais saudáveis e a higiene na produção é que irão garantir a segurança dos produtos.

A maturação do queijo Colonial artesanal pode ser realizada em temperatura ambiente, ambiente climatizado, área subterrânea ou câmara fria (acima de $5^{\circ} \mathrm{C}$ ). Quanto maior a temperatura, mais rápido é o processo, mas também é maior o risco de desenvolvimento de microrganismos indesejáveis. Pode-se utilizar prateleiras de madeira, plástico, aço inoxidável, fibra de vidro ou outro material aprovado.

Na maioria das vezes, os queijos são comercializados com poucos dias de maturação. Isso ocorre devido à preferência dos consumidores da região por queijos mais jovens, mais suaves, mas também pela limitação de espaço físico de alguns produtores. No entanto, a procura por queijos mais maturados tem aumentado.

Durante a maturação, o queijo Colonial artesanal pode ser imerso em vinho ou vinagre, o que proporciona uma coloração escura da casca e sabor característico.

\section{Parâmetros físico-químicos do queijo Colonial artesanal do Sudoeste do Paraná}

Em relação ao teor de umidade, o queijo Colonial artesanal classifica-se, de acordo com o Regulamento Técnico de Identidade e Qualidade de Queijos (BRASIL, 1996), como um queijo de baixa (até 35,9\%), média (36 - 45,9\%) ou alta umidade (46 - 54,9\%). Essa variação se dá devido à tecnologia de fabricação, que é variável entre os produtores, ao tempo e condições de maturação. 
Quanto ao teor de gordura no extrato seco (GES), o queijo Colonial artesanal é um queijo semigordo (25 - 44,9\%) ou gordo (45 - 59,9\%). O teor de gordura do leite utilizado na fabricação do queijo é o fator responsável por essa variação.

\section{Características sensoriais do queijo Colonial artesanal e percepção do consumidor}

O queijo Colonial apresenta coloração amarelada uniforme, produzido sem o uso de corantes, sabor e odor característicos, brando, ligeiramente ácido, pouco desenvolvido a pronunciado de acordo com o grau de maturação. De textura compacta, podendo apresentar olhaduras. Tem consistência semidura ou branda/macia, segundo o conteúdo de umidade, matéria gorda e grau de maturação. A crosta é fina ou de média espessura, sem trincas. O formato típico é cilíndrico, mas alguns produtores elaboram o queijo Colonial retangular (paralelepípedo).

A percepção do consumidor em relação ao queijo Colonial artesanal foi avaliada por meio da técnica de associação de palavras. Foi aplicado o seguinte estímulo: "Por favor, escreva as 4 primeiras palavras e/ou expressões que lhe vem à cabeça quando lê: "QUEIJO COLONIAL ARTESANAL". Todas as associações fornecidas pelos participantes foram analisadas, agrupadas e incluídas nos resultados. O teste foi realizado com 187 consumidores na 29a Expobel (Exposição, Feira Agropecuária, Industrial e Comercial de Francisco Beltrão), em março de 2020, durante uma degustação de queijos artesanais dos produtores associados à APROSUD, no Pavilhão da Agroindústria (SILVA et al., 2020).

A partir das respostas, percebeu-se o envolvimento afetivo dos consumidores com o queijo Colonial artesanal. Muitos associam o queijo à família, sentimentos nostálgicos como casa da mãe, casa da nona, infância, assim como também sentimentos como amor, alegria, carinho e prazer. Além disso, o uso culinário do queijo também pode ser observado fazendo parte do cotidiano das pessoas ao associar o queijo Colonial artesanal a outros alimentos como café com leite, omelete, pão, pão de queijo, lasanha, polenta, entre outros. Também foram citadas bebidas como vinho e cerveja, o que sugere que o queijo também é consumido como aperitivo/acompanhamento. As características sensoriais marcantes do queijo Colonial artesanal também foram citadas pelos consumidores como seu sabor, aroma, casca, formato redondo, queijo forte e cor amarela (SILVA et al., 2020).

A ligação do queijo com o território, o regionalismo também ficou claro nas respostas; tradição da região, agricultura familiar, Sudoeste, único, feito pelo produtor rural, cultura, diferenciado. Ressalta-se ainda a associação do queijo Colonial artesanal com leite fresco, leite cru, qualidade, confiança, feito à mão. Os termos nostálgicos levantados e também o fato de 
nenhum termo negativo ter sido encontrado nas respostas só reforça o contato positivo dos consumidores com o produto e a importância que o queijo Colonial artesanal tem para a região Sudoeste do Paraná (SILVA et al., 2020).

\section{Qualidade microbiológica do queijo Colonial artesanal do Sudoeste do Paraná}

O fato de o queijo Colonial artesanal ser produzido a partir do leite cru e sem adição de um inóculo inicial reconhecido (cultura starter), faz com que apresente uma população microbiana diversificada.

Em estudos preliminares sobre a microbiota do queijo Colonial artesanal, observou-se que estes queijos possuem naturalmente várias espécies de bactérias ácido láticas (BAL), caracterizadas como cocos ou bacilos Gram-positivos, não formadoras de esporos, imóveis, anaeróbicas facultativas, catalase-negativas e filogeneticamente distintas. Através de estudos moleculares e de proteômica realizados até o momento, observou-se que as bactérias láticas presentes nos queijos Coloniais artesanais do Sudoeste foram identificadas como Lactococcus garvieae, Lactococcus lactis, Leuconostoc mesenteroides, Enterococcus faecalis, Enterococcus faecium, Lactobacillus plantarum, Lactobacillus paracasei, Bacillus pumilus, Bacillus sonorensis, Staphylococcus saprophyticus e Enterococcus durans.

Esta microbiota ácido lática é essencial para o processo de fermentação e maturação dos queijos, pois são capazes de reduzir o pH pela produção de ácidos orgânicos, como o ácido lático, a partir da fermentação da lactose do leite, tornando-se o principal efeito antagonista contra diferentes tipos de microrganismos indesejáveis (HERMANNS, 2013). Além de reduzir o pH com os produtos metabólicos da fermentação, estas BAL são capazes de produzir peróxido de hidrogênio, bacteriocinas e substâncias bacteriostáticas, durante a fermentação lática, demonstrando seu potencial na conservação dos queijos, exercendo atividade antagonista do desenvolvimento de bactérias patogênicas e deterioradoras em alimentos (DHEWA, 2012). Além disso, as BAL vêm atraindo a atenção pelo papel probiótico que várias delas possuem, reforçando o grande interesse na utilização destas espécies em alimentos que favorecem a microbiota (MBYE et al., 2020).

No entanto, juntamente com a microbiota desejável, observou-se que este queijo pode conter populações variadas de coliformes totais e termotolerantes (Escherichia coli), várias espécies de Enterobacteriaceae, Staphylococcus spp. e em algumas amostras Salmonella spp., o que reforça a necessidade de maiores controles higiênicos na produção desses queijos. 


\section{Legislação para queijo Colonial artesanal}

O fortalecimento do movimento pela valorização dos queijos artesanais e a participação crescente do consumidor nesse processo tem demandado legislações apropriadas às agroindústrias de pequeno porte e aos produtores de queijos artesanais, especialmente aqueles elaborados com leite cru.

Novas normativas e legislações têm sido propostas (algumas já vigentes) a fim de possibilitar a formalização. Em 2017 foi publicada a revisão do Regulamento da Inspeção Industrial e Sanitária de Produtos de Origem Animal (RIISPOA) - Decreto n 9013/2017 que separa as exigências previstas para grandes estabelecimentos industriais e para os de pequeno porte (BRASIL, 2017a). As Instruções Normativas (INs) n 16/2015 e n 5/2017 do MAPA estabelecem os requisitos relacionados à estrutura física e equipamentos e determinam as diretrizes para o registro de estabelecimentos de pequeno porte (BRASIL, 2015; BRASIL, 2017b).

O RIISPOA/2017 também define que o período mínimo de maturação de queijos (de 60 dias) poderá ser alterado após a realização de estudos científicos conclusivos sobre a inocuidade do produto.

O Decreto $n^{\circ}$ 9.918/2019 dispõe sobre o processo de fiscalização de produtos alimentícios de origem animal produzidos de forma artesanal. Mais conhecido como Decreto do Selo ARTE, estabelece que os produtos alimentícios de origem animal produzidos de forma artesanal, além do selo do serviço de inspeção oficial, serão identificados por selo único com a indicação ARTE. Esses produtos poderão ser comercializados no território nacional (BRASIL, 2019a).

Complementar ao Decreto do Selo ARTE, a IN n 73/2019 estabelece o Regulamento Técnico de Boas Práticas Agropecuárias destinadas aos produtores rurais fornecedores de leite para a fabricação de produtos lácteos artesanais, necessárias à concessão do selo ARTE (BRASIL, 2019c).

Ainda em 2019, foi sancionada a Lei $\mathrm{n}^{\circ} 13.860 / 2019$ que dispõe sobre a elaboração e a comercialização de queijos artesanais. De acordo com essa lei, o tempo de cura do queijo feito a partir de leite cru é definido com base no processo tecnológico de produção de cada variedade de queijo, de acordo com suas características (BRASIL, 2019b).

Em dezembro de 2020, a Portaria $\mathrm{n}^{\circ} 186$ colocou em Consulta Pública a proposta de Instrução Normativa que estabelece os requisitos de boas práticas agropecuárias na produção leiteira; os requisitos de boas práticas de fabricação dos queijos artesanais; o modelo de protocolo de elaboração das características de identidade e qualidade do queijo artesanal, previstos pela Lei $\mathrm{n}^{\mathrm{o}}$ 13.860/2019 (BRASIL, 2020). 
No âmbito do estado do Paraná, a Lei estadual n 19.599/2018 regulamentou a fabricação e o comércio dos queijos artesanais produzidos a partir de leite cru (ALEP, 2018). A Portaria ${ }^{\circ}$ 81/2020 da Adapar estabelece os requisitos e critérios para adesão dos Municípios ou Consórcio de Municípios ao Sistema Unificado de Atenção à Sanidade Agropecuária, com atenção especial à Agricultura Familiar e de Pequeno Porte no Estado do Paraná (SUASA-SUSAF-PR). Para os estabelecimentos, a principal vantagem é a ampliação da área de comercialização de seus produtos, uma vez que, mesmo estando registrado no Serviço de Inspeção Municipal, podem comercializar em todo o território estadual (PARANÁ, 2020a).

\section{Principais dificuldades da produção de queijo Colonial artesanal}

Uma das principais dificuldades dos produtores de queijo Colonial artesanal é o registro do produto de leite cru. Apesar de a legislação permitir a fabricação de queijos artesanais a partir de leite cru, ainda existem alguns entraves. A certificação das propriedades como livres de tuberculose e brucelose é um deles, sendo o custo dos exames o principal motivo. A comprovação da inocuidade em período de maturação menor que 60 dias é outra dificuldade, visto que devem ser feitas análises microbiológicas dos queijos, que também demandam recursos financeiros por parte do produtor.

A contaminação microbiológica é uma preocupação em queijos elaborados com leite cru. Os microrganismos contaminantes mais prevalentes nos queijos artesanais brasileiros são coliformes e Staphylococcus. A espécie Staphylococcus aureus faz parte da microbiota normal de mucosas e pele, podendo ser transmitido aos alimentos por contato direto, principalmente mãos, ou indireto, como espirro e tosse. A contaminação dos queijos por estes microrganismos pode ser devido à falta de higiene do ordenhador e/ou manipulador que fabrica o queijo e/ou más condições de limpeza e sanitização das instalações e equipamentos. A contaminação por S. aureus também pode ocorrer em função de excreções provenientes da mastite clínica e subclínica. Sem dúvida, a mastite ainda é uma doença que causa prejuízos para a atividade leiteira e produção de queijos. A mastite caracteriza-se por um processo infeccioso na glândula mamária das vacas leiteiras, desenvolvendo uma reação inflamatória em resposta à infecção.

Os coliformes fermentam a lactose e produzem gás carbônico, causando pequenas olhaduras arredondadas ou irregulares, que quando presentes em grande número dão um aspecto de massa "rendada". Elevadas contagens de coliformes podem levar ao estufamento do queijo, denominado estufamento precoce. Esse problema é mais comum no verão, principalmente em 
queijos maturados à temperatura ambiente. Para evitar esse defeito, a qualidade do leite cru e as Boas Práticas de Fabricação são fundamentais.

A qualidade da água utilizada na ordenha e na fabricação do queijo também é um importante fator que deve ser considerado. A utilização de água contaminada contribui para a contaminação dos queijos. A água deve ser submetida a análises periódicas a fim de monitorar a potabilidade. O controle da cloração da água também é uma dificuldade para alguns produtores.

Outra dificuldade dos produtores é em relação ao controle da maturação. Um problema frequente é a formação de uma casca espessa no queijo que dificulta a maturação no interior. Isso pode ocorrer devido à umidade relativa muito baixa em câmaras de maturação, fluxo de ar intenso ou ainda à utilização de ar condicionado nas salas de maturação. Outro problema é o desenvolvimento não controlado de mofos na casca durante a maturação, os quais são indesejáveis no queijo Colonial.

O âmbito de comercialização dos queijos também é um entrave enfrentado pelos produtores. A maioria dos produtores de queijo Colonial artesanal tem inspeção municipal, o que permite a comercialização somente no município. Apesar da possibilidade de ampliar a venda para todo o estado através do SUSAF-PR ou para todo o país, através do selo ARTE, uma minoria de produtores obteve esses selos até o momento.

Para que o município possa solicitar seu cadastro junto ao SUSAF-PR, precisa ter um serviço de inspeção regulamentado, estruturado e ativo; médico veterinário responsável pelo SIM e ter a relação de estabelecimentos registrados no SIM em sítio eletrônico oficial do município. O estabelecimento interessado deve solicitar a sua indicação ao SUSAF-PR ao SIM onde possui seu registro. O SIM indicará apenas aqueles estabelecimentos que julgar aptos por atenderem aos critérios técnicos sanitários (PARANÁ, 2020a). No Paraná, a solicitação do selo ARTE foi atrelada ao SUSAF-PR. Segundo a Portaria n ${ }^{\circ}$ 175/2020 da Adapar, o SIM cujo estabelecimento estiver solicitando o Selo ARTE deverá estar aderido ao SUSAF-PR (PARANÁ, 2020b). Atualmente, somente cinco municípios de todo o estado aderiram ao SUSAF-PR. Destes, dois são da região Sudoeste (PARANÁ, 2020c).

Além disso, falta entendimento por parte de alguns profissionais que ainda insistem na padronização de processos e produtos no âmbito dos queijos artesanais. Não é possível definir fluxograma padrão, pois cada produtor faz o queijo da sua forma e é justamente esse saber-fazer diverso que dá a singularidade e a diversidade tão valorizadas pelo consumidor de queijo artesanal. Da mesma forma, não se pode atribuir características físico-químicas únicas, como umidade e GES, pois esses parâmetros variam entre os queijos devido àqueles modos de fazer diversos, como já comentado. Ainda, não é possível padronizar o tempo de maturação. A maturação de um queijo 
à temperatura ambiente é mais rápida do que a maturação em câmara fria. A microbiota inicial do leite cru, o tamanho do queijo e vários outros fatores interferem nesse processo. Por que precisamos que todos os queijos Coloniais sejam classificados da mesma forma e tenham o mesmo padrão? Por que precisamos que o queijo Colonial artesanal se encaixe em um RTIQ que pode limitar ou até excluir alguns produtores?

Muitas vezes, as exigências em instalações e equipamentos parecem ser superiores às exigências sobre a qualidade da matéria-prima, a sanidade dos animais, as boas práticas de fabricação e a qualidade final do produto, as quais deveriam se sobrepor a todas as demais (RIES; DA LUZ; WAGNER, 2012).

\section{Considerações finais e perspectivas futuras}

O Brasil ainda não acordou para a importância da diversidade de seus produtos produzidos artesanalmente, verdadeiras expressões da cultura do seu povo. Ao contrário, entende-os como produtos que precisam ser substituídos por produtos industriais, padronizados e "seguros". Os produtos artesanais também não são entendidos como ferramentas para um modelo de desenvolvimento sustentável, baseado na vocação das populações locais, e como instrumentos facilitadores para o desenvolvimento de outras atividades como, por exemplo, o turismo rural (RIES; DA LUZ; WAGNER, 2012).

Felizmente, por outro lado, alguns avanços têm sido observados nos últimos anos. Muitas ações vêm sendo desenvolvidas para melhorar a qualidade dos queijos artesanais, para resgatar e valorizar a história e cultura destes produtores, que vêm trabalhando arduamente, para viabilizar sua principal atividade econômica. É preciso apoiar os produtores que estão comprometidos com a qualidade dos queijos, a segurança dos alimentos e a manutenção da tradição.

Conforme apontado por Lima e Doula (2012), não se trata de, em nome da manutenção da tradição e da cultura, permitir que a legislação sanitária não seja cumprida. "Não defendemos aqui a visão romântica sobre a produção artesanal, que a representa de forma cristalizada e imutável, incapaz de se abrir às modificações que se processam a sua volta”. Entende-se a necessidade de algumas adequações para que não se coloque em risco a saúde do consumidor, mas deve-se atentar também de que forma essas adequações se darão sob pena de, aí sim, deturpar, descaracterizar ou mesmo suprimir o tradicional do queijo artesanal (LIMA; DOULA, 2012). Tentar padronizar a

produção artesanal é interferir no saber-fazer, na história, na cultura, na tradição. É colocar em risco a tipicidade de um produto regional, ligado ao território. 
O queijo Colonial artesanal do Sudoeste do Paraná tem forte potencial para Indicação Geográfica (IG), na modalidade Indicação de Procedência (IP), conforme apresentado no diagnóstico realizado pelo Sebrae em 2020. A principal função desta potencial IG será a de agregar valor ao produto final e principalmente proteger a região produtora, possuindo um papel fundamental na proteção histórica e cultural local (SEBRAE, 2020).

Nesse contexto, a produção do queijo Colonial artesanal precisa atender a todos estes quesitos aqui abordados para garantir sua legitimidade e alcançar públicos e mercados mais abrangentes, sem, contudo, perder sua característica de produto da agricultura familiar, mantendo sua tradição e cultura aliada à segurança alimentar.

\section{Agradecimentos}

À UTFPR, CNPq, Fundação Araucária e Central Cresol Baser pelo apoio financeiro. Ao MAPA, Emater-PR (IDR-PR), Sebrae-PR, APROSUD e a todos os produtores de queijo.

\section{Referências}

ALEP. Assembleia Legislativa do Estado do Paraná. Lei n 19.599, de 17 de julho de 2018. Dispõe sobre a produção e a comercialização dos queijos artesanais no Estado do Paraná. Diário Oficial $\mathrm{n}^{\circ}$. 10233 de 18 de julho de 2018. Disponível em: http://portal.alep.pr.gov.br/modules/mod_legislativo_arquivo/mod_legislativo_arquivo. php?leiCod=51524\&tipo=L\&tplei=0. Acesso em: 15 agosto 2018.

BADARÓ, A. C. L.; CASTRO CISLAGHI, F. P. (Org.). Segurança alimentar na produção de Queijos. Queijo Colonial artesanal. Volume 2. 1. ed. Francisco Beltrão: Grafisul, 2019. v. 2. 200p.

BRASIL. Decreto $n^{\circ}$ 9.013, de 29 de março de 2017. Regulamenta a Lei ${ }^{\circ} 1.283$, de 18 de dezembro de 1950, e a Lei $\mathrm{n}^{\circ} 7.889$, de 23 de novembro de 1989, que dispõem sobre a inspeção industrial e sanitária de produtos de origem animal. Diário Oficial da União, 30 março 2017a.

BRASIL. Ministério da Agricultura, Pecuária e Abastecimento. Instrução Normativa ${ }^{\circ} 5$, de 14 de fevereiro de 2017. Estabelece os requisitos para avaliação de equivalência ao Sistema Unificado de Atenção à Sanidade Agropecuária relativos à estrutura física, dependências e equipamentos de estabelecimento agroindustrial de pequeno porte de produtos de origem animal. Diário Oficial da União, seção 1, no 33, p. 3-6, 15 de fevereiro de 2017b.

BRASIL. Ministério da Agricultura, Pecuária e Abastecimento. Instrução Normativa ${ }^{\circ}$ 16, de 23 de junho de 2015. Estabelece, em todo o território nacional, as normas específicas de inspeção e a fiscalização sanitária de produtos de origem animal, referente às agroindústrias de pequeno porte. Diário Oficial da União, 24 de junho de 2015.

BRASIL. Ministério da Agricultura, Pecuária e Abastecimento. Instrução Normativa ${ }^{\circ}$ 73, de 23 de dezembro de 2019. Regulamento Técnico de Boas Práticas Agropecuárias destinadas aos produtores rurais fornecedores de leite para a fabricação de produtos lácteos artesanais, necessárias à concessão do selo ARTE. Diário Oficial da União, 30 de dezembro de 2019c. 
BRASIL. Ministério da Agricultura, Pecuária e Abastecimento. Portaria nº 146, de 07 de março de 1996. Regulamento Técnico de Identidade e Qualidade de Queijos. Diário Oficial da União, 07 de março de 1996.

BRASIL. Ministério da Agricultura, Pecuária e Abastecimento. Portaria n ${ }^{\circ}$ 186, de 9 de dezembro de 2020. Submete à Consulta Pública, pelo prazo de 45 (quarenta e cinco) dias, a contar da data da publicação desta Portaria, a proposta de Instrução Normativa, que estabelece os requisitos para a elaboração de queijo artesanal para atendimento à Lei n. ${ }^{\circ} 13.860$, de 18 de julho de 2019. Diário Oficial da União, 11 de dezembro de 2020.

BRASIL. Presidência da República. Decreto nº 9.918, de 18 de julho de 2019. Regulamenta o art. 10-A da Lei $\mathrm{n}^{\circ} 1.283$, de 18 de dezembro de 1950, que dispõe sobre o processo de fiscalização de produtos alimentícios de origem animal produzidos de forma artesanal. Diário Oficial da União, 19 de julho de 2019a.

BRASIL. Presidência da República. Lei $\mathrm{n}^{\circ}$ 13.860, de 18 de julho de 2019. Dispõe sobre a elaboração e comercialização de queijos artesanais e dá outras providências. Diário Oficial da União, 19 de julho de $2019 b$.

BOTTELLI, F. The terroir concept for food products: the case of the cheese market in Brazil. 2020. 41 f. Dissertação (Mestrado profissional MPGI) - Fundação Getúlio Vargas, Escola de Administração de Empresas de São Paulo, 2020.

CASTRO CISLAGHI, F. P.; FIEBIG, M. S.; SILVA, T. C.; ABREU, Y. S. M.; BADARÓ, A. C. L. Mapeamento dos produtores e aspectos de qualidade do queijo Colonial artesanal da região Sudoeste Paranaense. In: $37^{\circ}$ SEMINÁRIO DE EXTENSÃO UNIVERSITÁRIA DA REGIÃO SUL (37 SEURS). Anais. 2019.

CASTRO CISLAGHI, F. P.; BADARÓ, A. C. L. (Org.). Segurança alimentar na produção de Queijos. Queijo Colonial artesanal. Volume 1. 1. ed. Francisco Beltrão: Grafisul, 2019. v. 2. $162 \mathrm{p}$.

DHEWA, T. Screening, production purification and potential use of bacteriocins from lactic acid bactéria of meat and dairy food origin. In: INTERNATIONAL CONFERENCE ON NUTRITION AND FOOD SCIENCES, 2012, Singapore. Proceedings [...]. Singapore: IACSIT Press 2012, 39:35-41.

DORIGON, C. Mercados de produtos coloniais da Região Oeste de Santa Catarina: em construção. In: IV ENEC - ENCONTRO NACIONAL DE ESTUDOS DO CONSUMO. Anais. 2008. Disponível em: http://estudosdoconsumo.com/wp-content/uploads/2018/03/enec2008clovis_dorigon.pdf. Acesso em 15 julho 2019.

FREITAS EDUARDO, M. A dinâmica territorial das agroindústrias artesanais de Francisco Beltrão/PR. 2008. 166p. Dissertação (Mestrado em Geografia). Universidade Estadual Paulista, Presidente Prudente, 2008.

HERMANNS, G. Potencial bacteriocinogênico e probiótico de bactérias ácido láticas isoladas de leite e queijos artesanais. 2013. 100p. Tese (Doutorado) - Programa de Pós-Graduação em Ciências e Tecnologia de Alimentos, Universidade Federal de Santa Maria, Santa Maria - RS, 2013. 
IBGE. Instituto Brasileiro de Geografia e Estatística. 2017. Disponível em: https://cidades.ibge.gov.br/brasil/pr/panorama. Acesso em: 15 julho de 2019.

LIMA, R.S.; DOULA, S.M. A tradição e a lei - o queijo Minas artesanal e os impasses da legislação sanitária no impedimento de sua comercialização fora do estado de MG. Faz Ciência, v. 14, p. 181-195, 2012.

MATOS, L. A. I.; LA ROVERE, R. L. Tipos de conhecimento regional protegidos pelas instituições na indicação de procedência Canastra (MG). Revista de Economia e Sociologia Rural, v. 58, e188623, 2020.

MBYE, M. et al. Updates on understanding of probiotic lactic acid bacteria responses to environmental stresses and highlights on proteomic analyses. Comprehensive Reviews in Food Science and Food Safety, v. 19, p. 1110-1124, 2020.

PARANÁ. Agência de Defesa Agropecuária do Paraná - Adapar. Portaria n ${ }^{\circ} \mathbf{0 8 1}$, de 29 de abril de 2020. Estabelece os requisitos e critérios para adesão dos Municípios ou Consórcio de Municípios ao Sistema Unificado de Atenção à Sanidade Agropecuária, com atenção especial à Agricultura Familiar e de Pequeno Porte no Estado do Paraná (SUASA-SUSAF-PR). Disponível em:

http://www.adapar.pr.gov.br/sites/adapar/arquivos_restritos/files/migrados/File/ATG/AIC/Image ns/anexo234182 539341.pdf. Acesso em: 17 dezembro 2020a.

PARANÁ. Agência de Defesa Agropecuária do Paraná - Adapar. Portaria no 175, de 07 de agosto de 2020. Dispõe sobre os procedimentos para a concessão do selo ARTE a produto alimentício de origem animal registrado em Serviço de Inspeção Oficial, produzido de forma artesanal no Estado do Paraná. Disponível em: http://www.adapar.pr.gov.br/sites/adapar/arquivos_restritos/files/documento/202012/portaria_adapar_175_2020__selo_arte_pr.pdf. Acesso em: 18 dezembro 2020b.

PARANÁ. Agência de Defesa Agropecuária do Paraná - Adapar. SUSAF - Sistema Unificado Estadual de Sanidade Agroindustrial Familiar, Artesanal e de Pequeno Porte. Disponível em: http://www.adapar.pr.gov.br/Pagina/SUSAF-Sistema-Unificado-Estadual-de-SanidadeAgroindustrial-Familiar-Artesanal-e-de-Pequeno. Acesso em 18 dezembro 2020c.

PASTRO, J.; FURLANI, L. L.; CASTRO CISLAGHI, F. P.; BADARÓ, A. C. L. Qualificação, valorização e RTIQ do queijo Colonial artesanal do Sudoeste do Paraná. In: X SEMINÁRIO DE EXTENSÃO E INOVAÇÃO DA UTFPR (X SEI). Anais. 2020.

PEHRSON, M.E.S.F. Efeito da adição de culturas probióticas sobre aspectos microbiológicos e parâmetros fermentativos de Queijo Artesanal das Terras Altas da Mantiqueira. 2017. 126p. Tese (Doutorado em Ciências) - Escola de Engenharia de Lorena, Universidade de São Paulo, Lorena - SP, 2017.

RIES, J. E.; DA LUZ, J. C. S.; WAGNER, S. A. Projeto de qualificação e certificação do queijo Serrano produzido nos Campos de Cima da Serra do Rio Grande do Sul - relato parcial da experiência. Agroecologia e Desenv. Rural Sustentável, v. 5, p. 10-19, 2012.

ROCHA, A. A.; BARCHET, I. O rural e o urbano no estado do Paraná. Boletim de Geografia, Maringá, v. 33, n. 2, p. 115-126, 2015. 
SALDANHA, R. K. O perfil da agricultura familiar do Sudoeste Paranaense segundo o histórico da economia agrícola da região e as estatísticas mais recentes. 2014. Monografia (Graduação em Ciências Econômicas). Universidade Federal do Paraná, Curitiba, 2014.

SEAB/DERAL. LEITE - Análise da Conjuntura Agropecuária 2019/2020. Prognóstico Ano 2019/20. 2020.

Disponível em:

http://www.agricultura.pr.gov.br/sites/default/arquivos_restritos/files/documento/202001/leite_2020_0.pdf. Acesso em: 15 dezembro 2020.

SEBRAE. Serviço Brasileiro de Apoio às Micro e Pequenas Empresas. Avaliação do Potencial de IG para o Queijo Colonial do Sudoeste do Paraná. Paraná, 2020.

SILVA, T. C.; CASTRO CISLAGHI, F. P.; PASTRO, J.; MARQUES, C.; BADARÓ, A. C. L. Análise sensorial do queijo Colonial artesanal do Sudoeste do Paraná. In: XXV SEMINÁRIO DE INICIAÇÃO CIENTÍFICA E TECNOLÓGICA DA UTFPR (XXV SICITE), Anais. 2020.

SILVA, F.; SILVA, G.; TONIAL, I.B.; CASTRO-CISLAGHI, F.P. Qualidade microbiológica e físico-química de queijos coloniais com e sem inspeção, comercializados no Sudoeste do Paraná. Boletim CEPPA, v. 33, p. 33-44, 2015.

SOBRAL, D. et al. Principais defeitos em queijo Minas artesanal: uma revisão. Rev. Inst. Laticínios Cândido Tostes, Juiz de Fora, v. 72, n. 2, p. 108-120, 2017.

Recebido em: 17/12/2020 Aprovado em 08/02/2021 